\title{
دراسة الظروف المناخية المؤثرة علي "دير قبة الهواء" بأسوان \\ Study The Effect of Climatic Conditions On "Qubbet El-Hawa Monastery " Aswan
}

\author{
أسماء محمد بشير, 2 حسين محمد علي

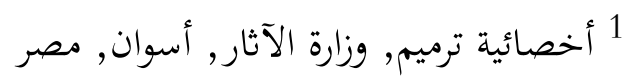

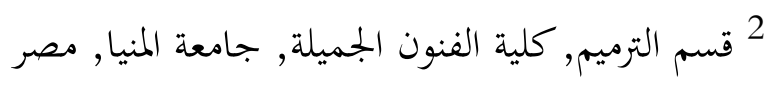

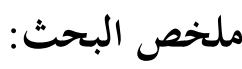

نظراً لأهمية دير قبة الهواء الأثرية والتاريخية حيث أنه عبارة عن دير أثري يتميز بموقعه الفريد ,

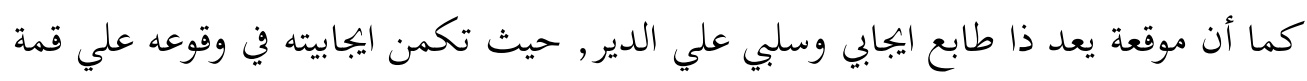

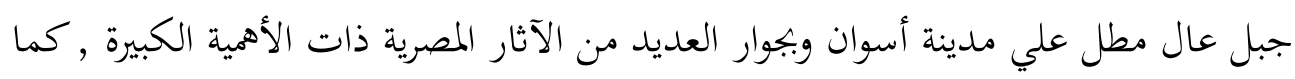

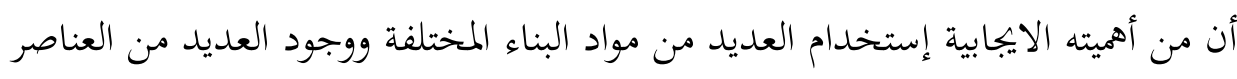

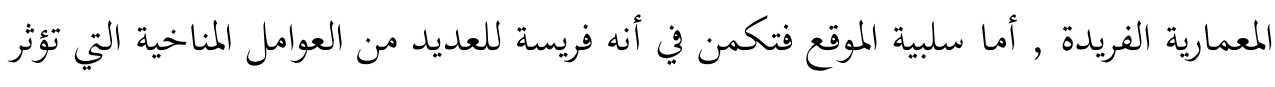

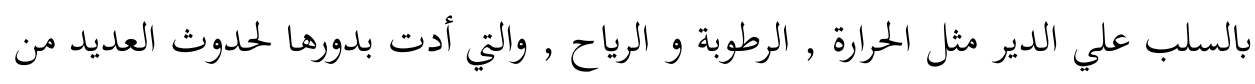

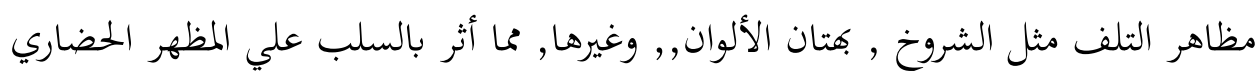
والجمالي للدير.

1

يستمد هذا الدير أسمه من التل المرتفع بغرب النيل ويطل عليه في مواجهة مدينة أسوان مباشرة,

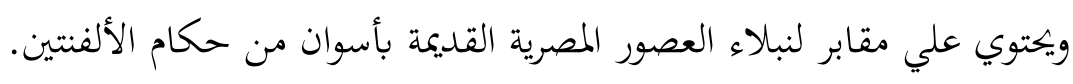

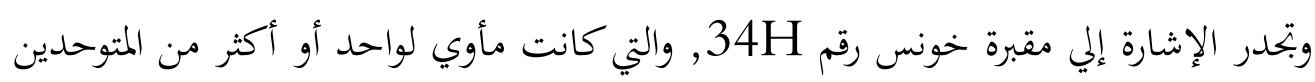
إيان العصر المسيحي قد تطورت إلي دير أسماه بوكوك 


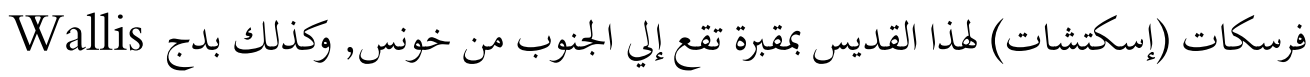
و وميناردوس Otto Meinarduse

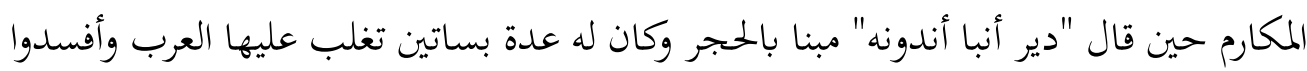
الدير", مما يرجع خراب الدير في القرن الثاني عشر للميلاد.

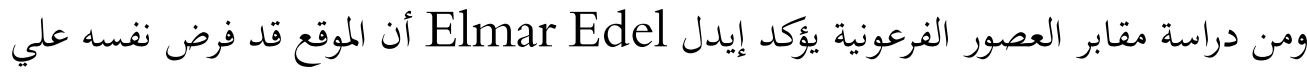
تخطيط الدير, لأن العديد من تلك المقابر كانت قد إستغلت للإقامة والعبادة بواسطة الرهبان

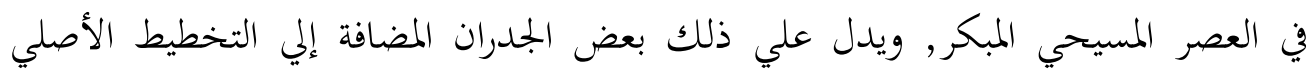
للمقابر , وبقايا الكتابات القبطية المخطوطة علي طبقات الملاط التي طليت بها.

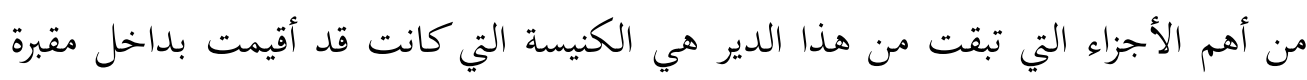

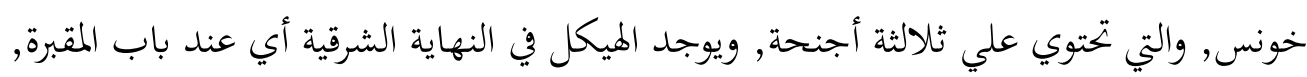

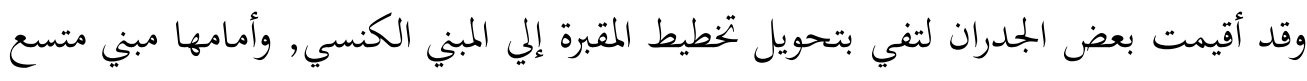

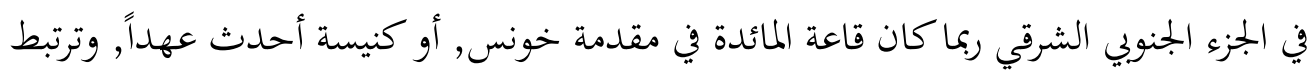

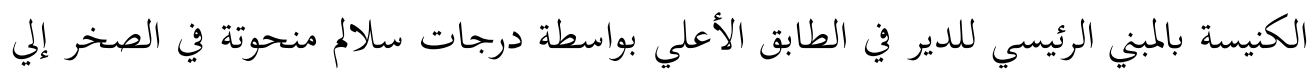

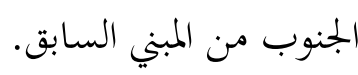
المبني بأعلي المقابر محاط بسور من الطوب اللبن, وله مدخل في الجهة الشمالية يفتح علي السلم

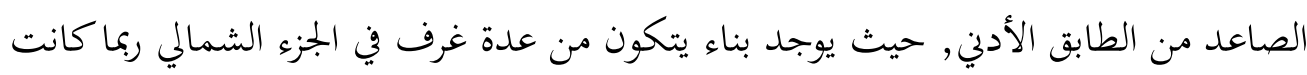

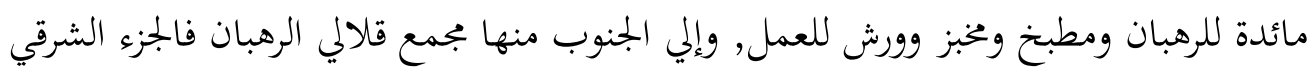

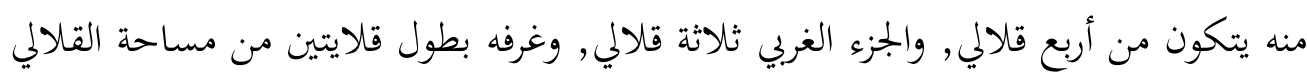

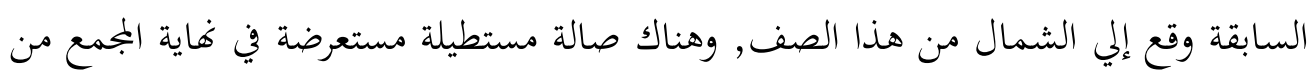

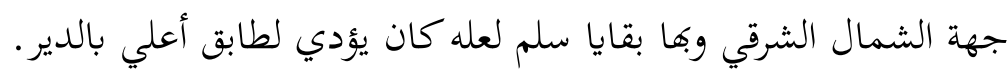

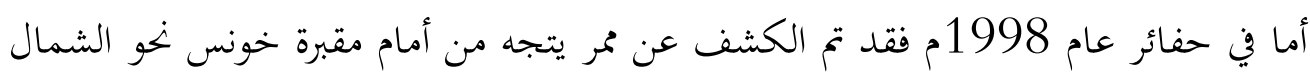

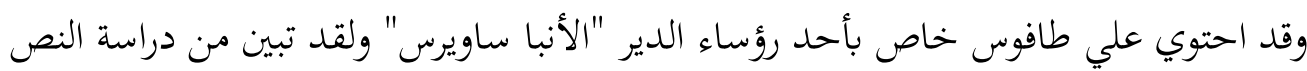

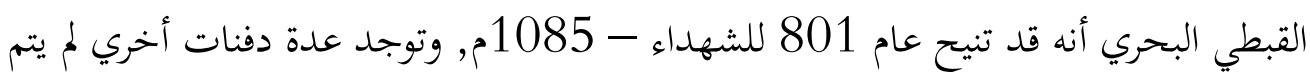
الكشف عنها بعد.(صورة1) 


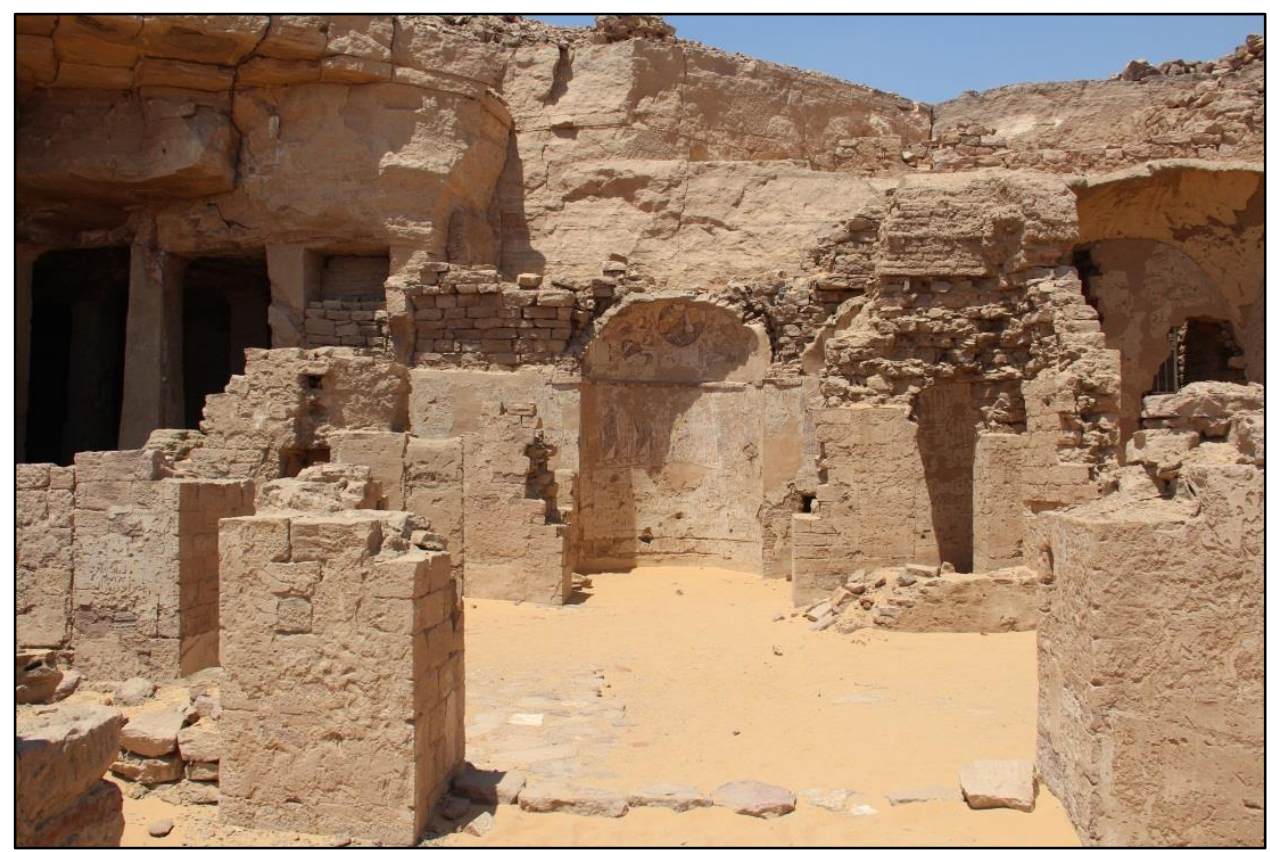

$$
\text { (صورة1) دير قبة الهواء بأسوان }
$$

تقع إلي الشمال الرقي من الطافوس وسلم الزيارة الحالي لمنطقة المقابر , تبلغ أبعادها 17.5م

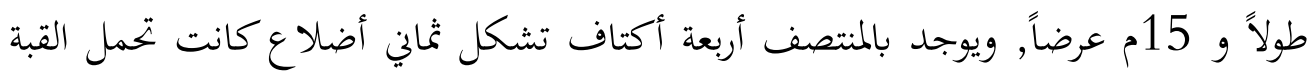

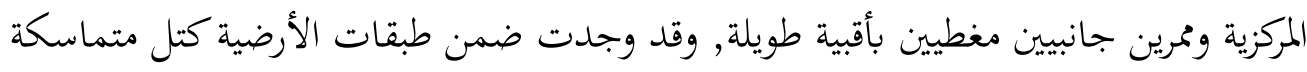
من الأقبية و العقود المتساقطة تثبت وجود هذه الأسقف, وباقي منها أجزاء في أعلي الجحدران بالجانب الغربي. في الجهة الغربية يوجد قبو أسطواني يمتد من الشمال إلي الجنوب وبأسفله سلم يؤدي إلي غرفه بأعلي الكنيسة, وإلي الشمال توجد فتحة باب تؤدي إلي مقبرة محفورة في الصخر (شأن مقابر

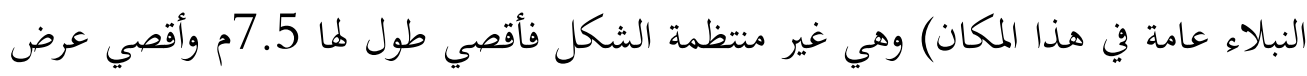

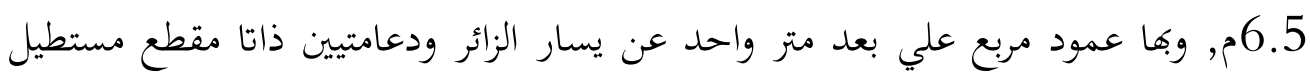
يفضل المساحة إلي ما يشبه حجرتين غير متساويتين. في منتصف الجدار الشرقي توجد فتحه مستطيلة صغيرة تؤدي إلي قبو يتسع لشخصين راكعين, وبالركن الشمالي منه فتحة صغيرة تتصل 
بالمبني الكنسي. الجمدار الشرقي بأكمله مشيد من الحجر ومضاف إلي المقبرة الأصلية المنحوتة, وقد غطيت المقبرة بطبقة من الملاط وصور عليها خمس صلبان بعصها تتخلله زخارف نباتية والبعض ذو لون أصفر والأخر ملون بالبنفسجي. وهذه القلاية Hermitage لعلها كانت النواة الأولي لدير قبة الهواء وتطور عنها المبني الكنسي السابق.

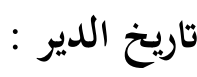
هناك عدة عصور يمكن أن تؤرخ من خلال حفائر عام 1998م, فالكنيسة المكتشفة وجدت علي إحدي دعاماتا كتابة قبطية تحتوي علي إسم البابا يعقوب البطريرك الخمسين (819830م) وربما هذا تاريخ بتديدها, والصلبان بداخل القلاية والتصاوير الموجودة علي الجدار الغربي قد نفذت باللون البنفسجي والذي يؤرخ في تصاوير النوبة المسيحية بالقرن الثامن الميلادى, ولذلك فالدير يرجع إلي ما قبل القرن الثامن وإستمر حتي القرن الثاني عشر للميلاد, ولكن فترة

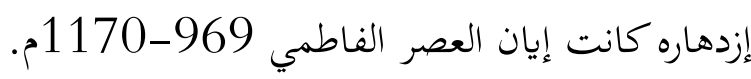
ويوجد بالدير نص قصير باللغة النوبية, وعلي أي حال فهو ذو إرتباط وثيق بأديرة الكوبانية والأنبا هدرا بغرب أسوان من ناحية, ويرتبط أيضاً بمواطن الرهبنة في النوبة المسيحية من ناحية

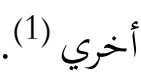

\section{التصاوير الجمدارية : n}

تحت القبو الأول وعلي الجمدار الغربي للكنيسة يوجد رسم للسيد المسيح وعن يمينه خمس أشخاص تزدان رأس كل منهم بهالة مستطيلة باللون الأصفر وهم يرتدون ثياباً فضفاضة ملونة باللون البني

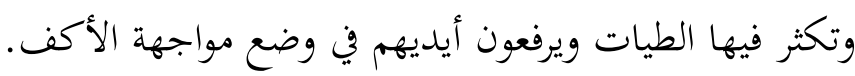
وإلي الجنوب من الرسم السابق يوجد بتوييف جداري بشكل حنية نصف دائرية بأعلاها صورة السيد المسيح جالساً علي عرشه حاملاً البشارة بيسراه مستنده علي ركبنه, وبيده اليمني يعطي إشارة البركة بإصباعية السبابة والوسطي, وهذا المنظر المعروف بإسم السيد المسيح ضابظ الكل Pantocrator

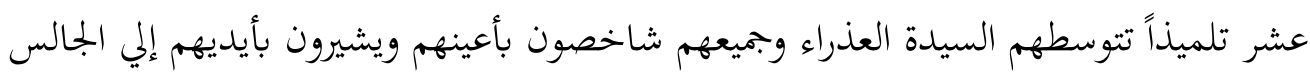


علي العرش, وهو موضوع تكرر فيما سبق في دير الأنبا أبوللو بباويط ودير الأنبا أرميا بسقارة,

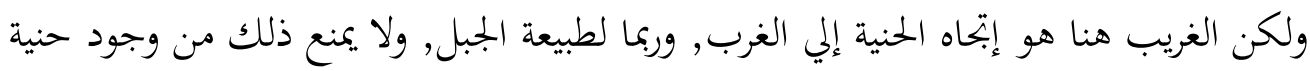
في الجدار الشرقي للكنيسة الذي لم يتبقي منه الكثير . وقد نفذت التصاوير الجدارية بالدير بإسلوب التمبرا, ,

: 2 بيئة أسوان المناخية

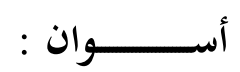

مدينة أسوان هي عاصمة محافظة أسوان تقع محافظة أسوان جنوب جمهورية مصر العربية ، ويحدها من الشمال محافظة الأقصر، وشرقا محافظة البحر الأحمر، وغربا محافظة الوادي الجلديد، وجنوبا السودان عند خط عرض 22 شمال مدار السرطان ، وترتفع مدينة أسوان حوالي 85 متر فوق سطح البحر، وتبعد عن القاهرة 879 كم، وتبلغ مساحة المحافظة 34,608 كم2 (2). (خريطة 1)

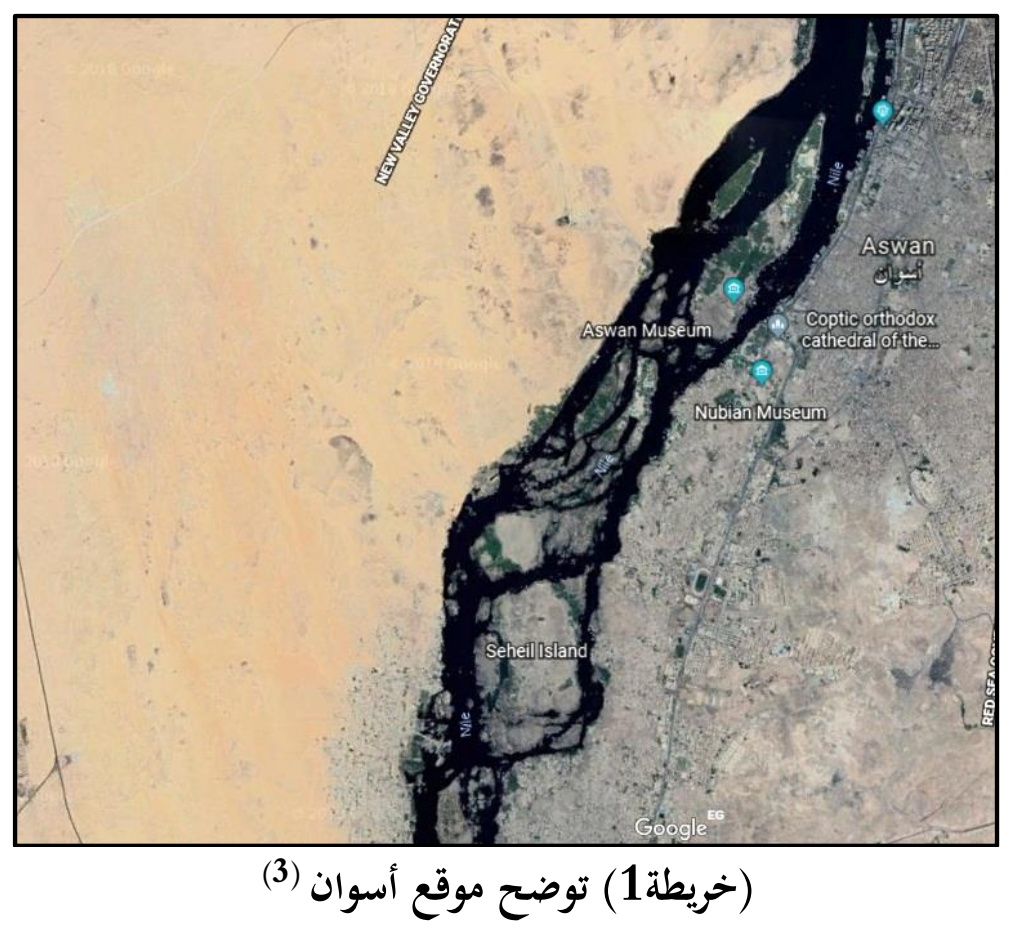


كما تعتبر أسوان أهم مدن النوبة المنطقة الحضارية التي طلما ظلت البوابة الجنوبية لمصر، تقع المدينة على الضفة الشرقية لنهر النيل عند الشلال الأول. يصلها بالقاهرة خط سكة حديد وطرق برية صحراوية وزراعية ومراكب نيلية ورحلات جوية محلية. ويبلغ عدد سكانها تقريبا 900

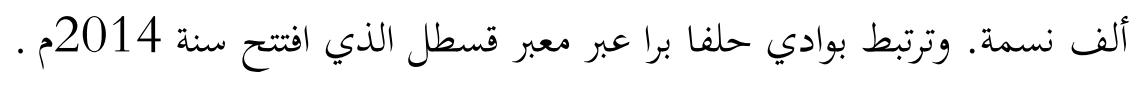
كانت أسوان تعرف باسم " سونو " في عصور المصريين القدماء ومعناها السوق حيث كانت

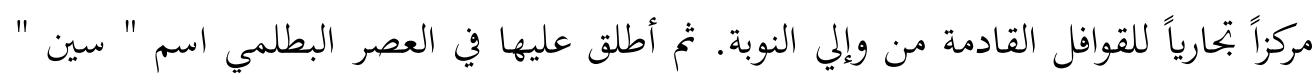

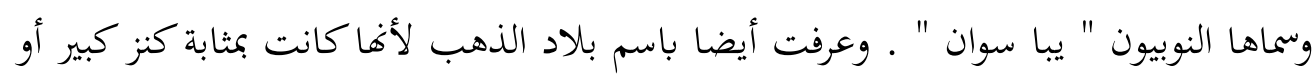

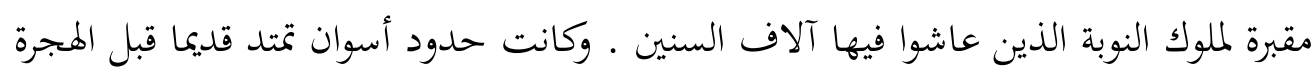

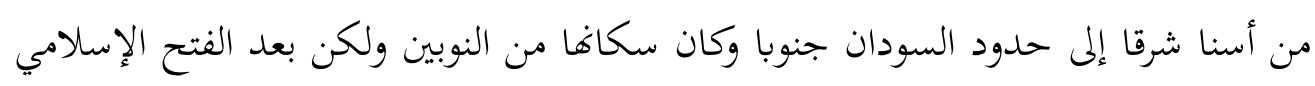

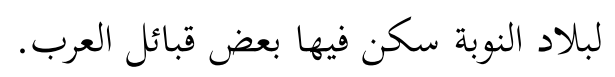

\section{التضاريس : (1) n تنقسم أسوان إلي :} 1 - الجزء السهلي من المدينة وهو يمثل الذي لا يحف بالنيل ,وهو ضيق الرقعة في الجنوب

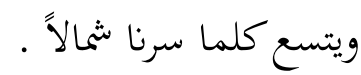
2 - الجزء المتوسط الإرتفاع وهو ربوة عالية تمثل أسوان القديمة , والتي أخذت تتسع شرق وغرب المنطقة الصحراوية التي تمتد شرق أسوان وغرب النيل .

مناخ أسوان يدخل ضمن الأقليم الصحراوي الذي يمتد من المنيا حتي أسوان , وهو مناخ حار

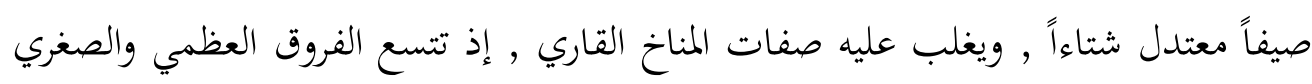

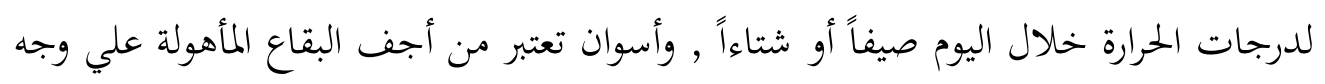


الأرض , فعلي سبيل المثال لم تسقط أى أمطار في الست سنوات من 1995 : 2001م.

(صورة 2)

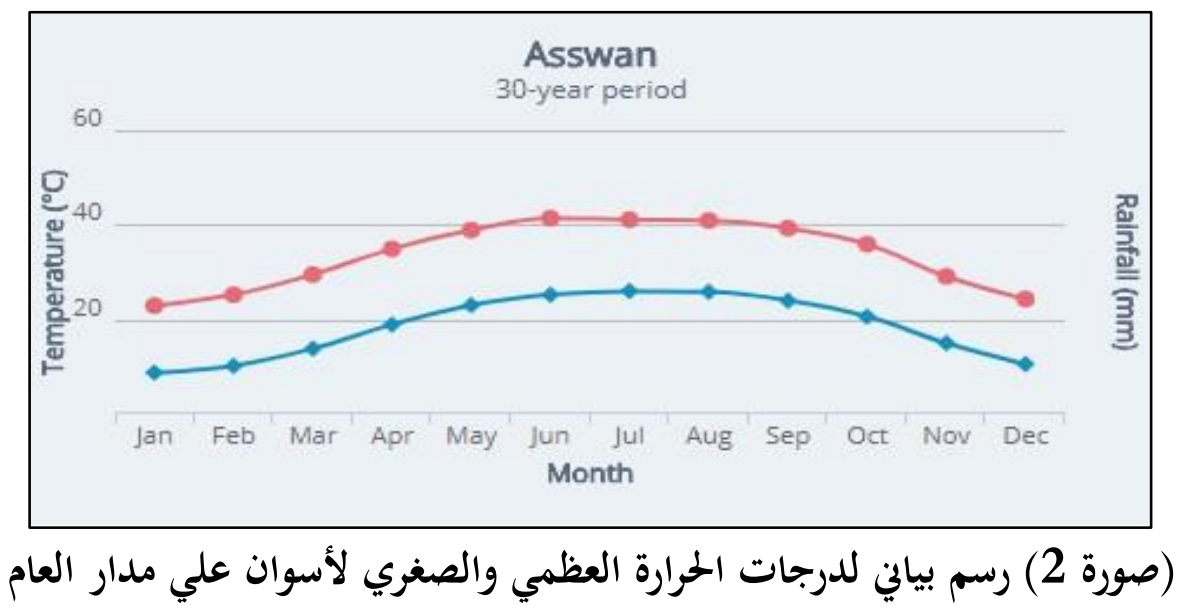

3_العوامل المناخية المؤثرة علي دير قبة المواء :

3_3_التفاوت في درجات الحرارة : 
تعد الشمس المصدر الرئيسي لحرارة الأرض حيث ينبعث منها الأشعة متجهة إلي الأرض

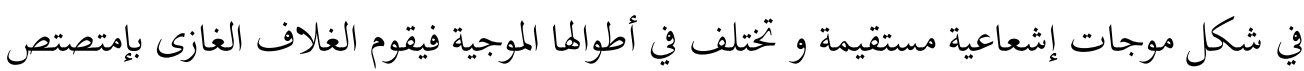

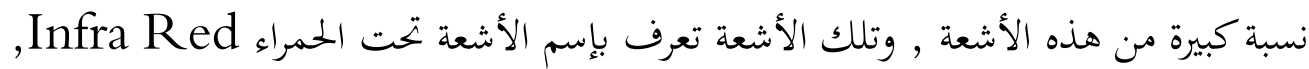

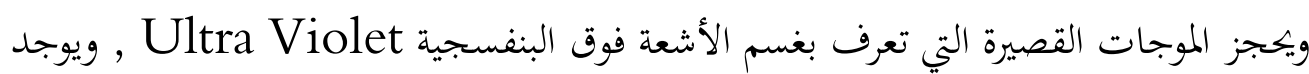

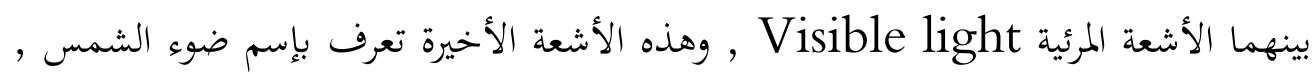

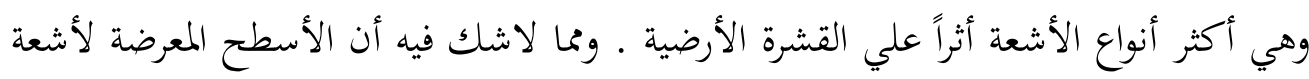

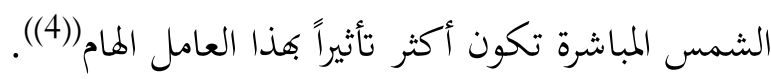

ويدخل مناخ أسوان ضمن الأقليم الصحراوي الذي يمتد من المنيا حتي أسوان , أي أنه يدخل

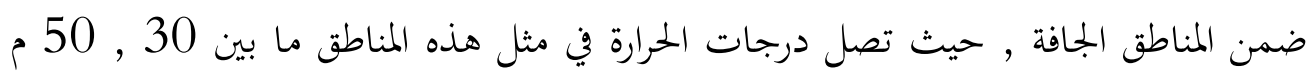

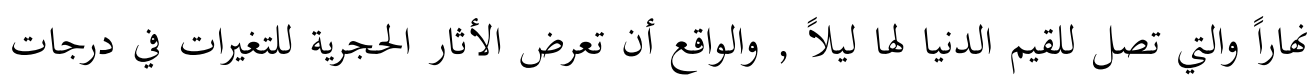

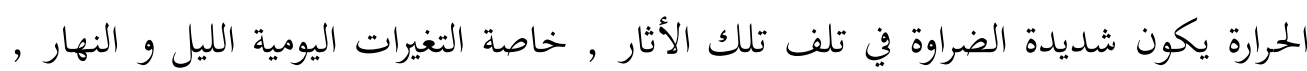
خاصة في مثل هذه المناطق الحارة من صعيد مصر (5). تعتبر التغيرات في درجات الحرارة من العوامل الميكانيكية المدمرة , ويكون تأثيرها فعالاً عندما

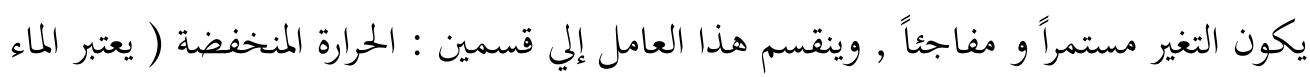

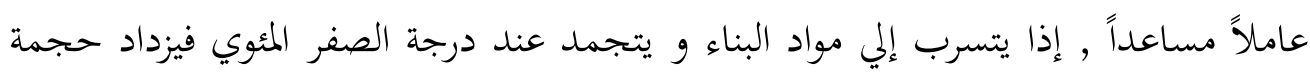

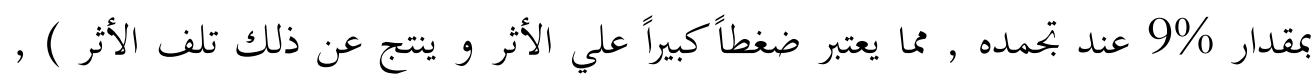

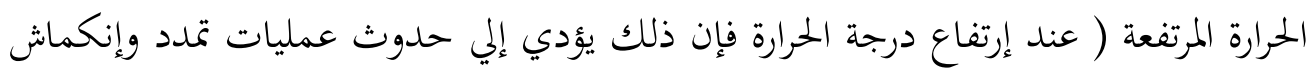

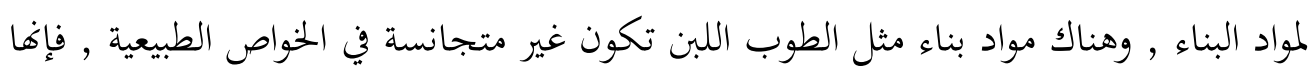
تتمدد وتنكمش بدرجات مختلفة ومتفاوتة ).

ومما سبق كان لابد لنا من دراسة درجات الحرارة الجوية بمنطقة أسوان والتي يوجد بها دير قبة

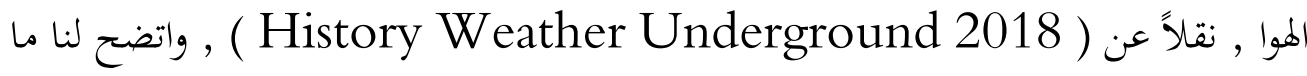
يلي : - أعلي متوسط لدرجات الحرارة الشهرية العظمي 43 درجة مئوية لشهر يوليو 2017م . 
- أقل متوسط لدرجات الحرارة الشهرية العظمي 24 درجة مئوية لشهر يناير 2017م .

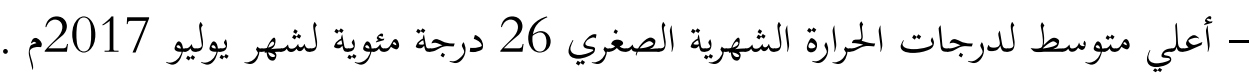

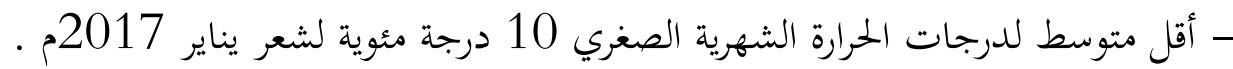
و في خلال الأعوام الأخيرة من 2013 : 2017م بلغت أعلي درجة حرارة شهرية عظمي 38 درجة مئوية خلال شهر يوليو لعام 2014م , و و بلغت أدني درجة حرارة شهرية صغري 3 درجة مئوية خلال شهر يناير 2015م. (جدول 1) (صورة 3) مئل

\begin{tabular}{|c|c|c|c|c|c|}
\hline 2017 & 2016 & 2015 & 2014 & 2013 & درجة الحرارة \\
\hline 43 & 42 & 42 & 42 & 41 & متوسط العظمي \\
\hline 28 & 28 & 27 & 29 & 27 & متوسط الصغري \\
\hline
\end{tabular}

(جدول11) يوضح متوسط درجات الحرارة العظمي والصغري علي مدينة أسوان لشهر يوليو خلال الأعوام 2013م إلي 2017م 


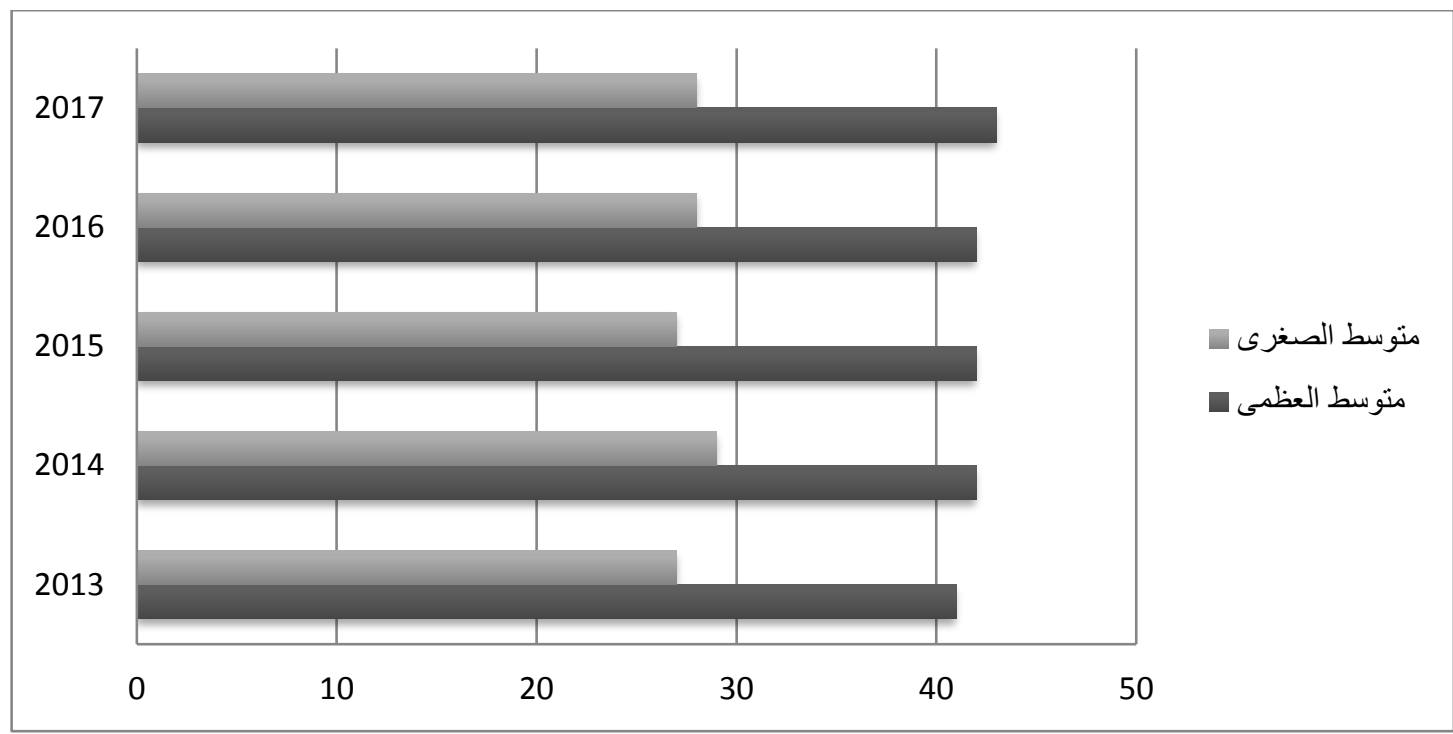

(صورة 3) رسم بياني يوضح متوسط درجات الحرارة العظمي والصغري علي مدينة أسوان

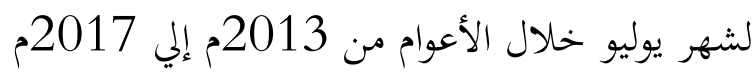

ويتضح من خلال ما سبق التعرض للتغير المستمر في درجات الحرارة سواء أكان موسمياً أو شهرياً

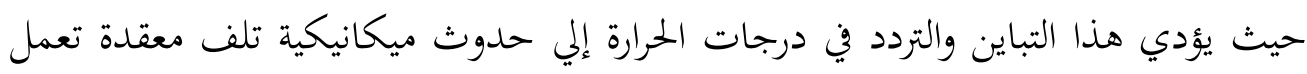
علي تلف المباني الأثرية وما تحتوية من صور جدارية ـ علي سبيل المثال فإن الطبقة الخارجية لسطح الحجر لو تعرضت لأشعة الشمس المباشرة و الحرارة فإنها تمتص طاقة حرارية عالية من

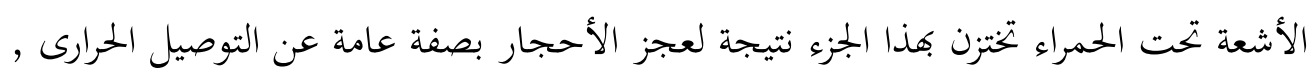
ويؤدي ذلك إلي إرتفاع ملحوظ في درجة حرارة السطح و صعوبة كبيرة في تسريب الحرارة

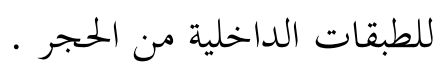

وتزداد هذه المشكلة ويظهر تأثيرها واضحاً في الصخور الغير مسامية وخاصة النارية و الكثير من

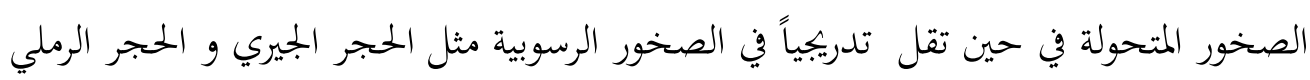

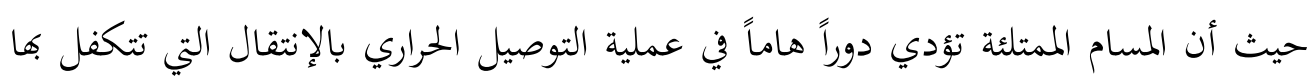
دورة المواء في هذه المسام(6). 
وعلي مدار اليوم يكون جزءاً كبيراً من حرارة السطح قد تسرب ببطئ غنو الداخل في حين يكون

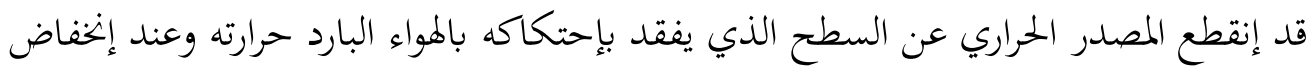

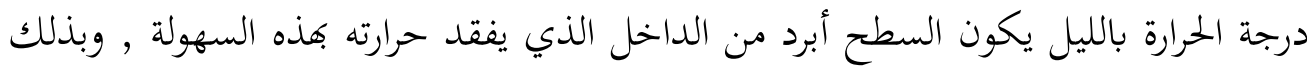

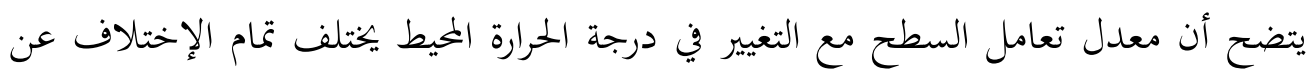

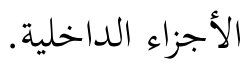

ونتيجة لإختلاف معدل تعامل السطح من التغير في درجة الحرارة الميطة عن الأجزاء الداخلية , فإنه تحدث لتلك الجدران والتي تعمل صوراً جدارية ظاهرتان : - الظاهرة الأولي : حيث أن الصخر يتكون من عدد قليل من المعادن المختلفة الخواص الحرارية

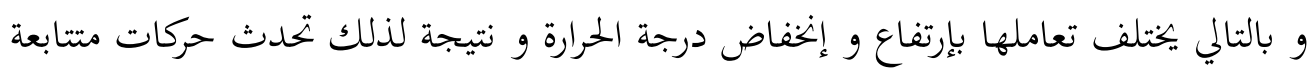

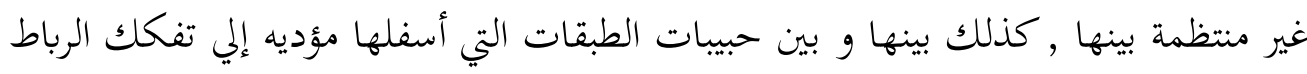

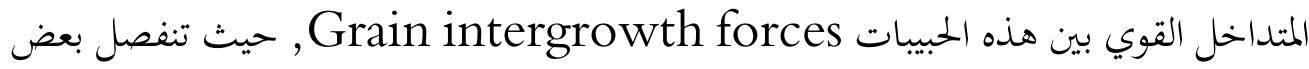

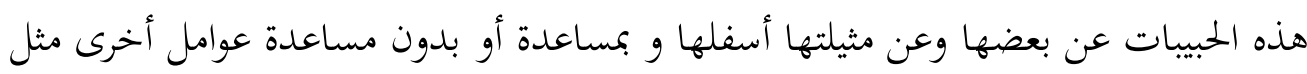

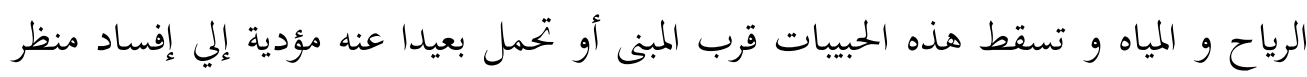

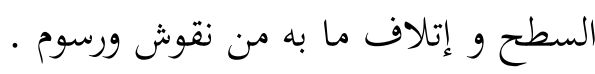

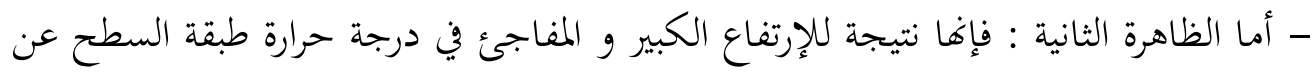

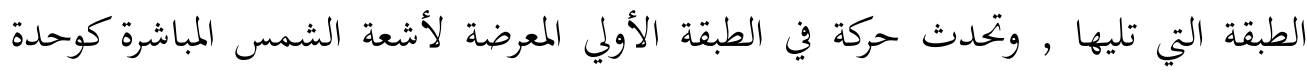

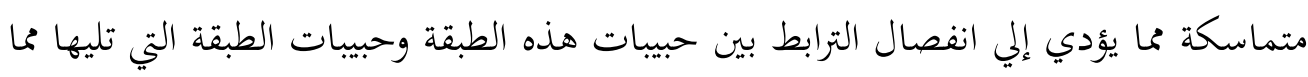
ينتج عنه إنفصال قشور Scales أو طبقات سطحية Layers بأكملها و تساقطها متلفة

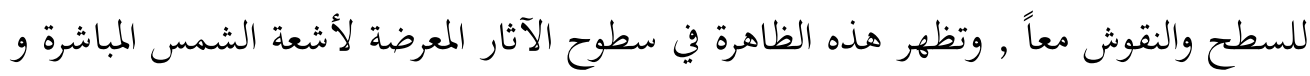

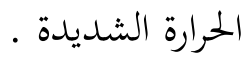

وبتكرار هاتان الظاهرتان قد نصل في بعض الأحيان ليس فقط لإتلاف السطح والنقوش , بل أيضاً كل الوحدات المعمارية ذاتا. 
كما تتعرض أسطح الصور الجدارية القبطية و بخاصة تلك التي توجد في الأماكن الصحراوية

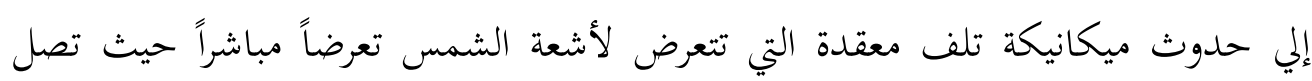

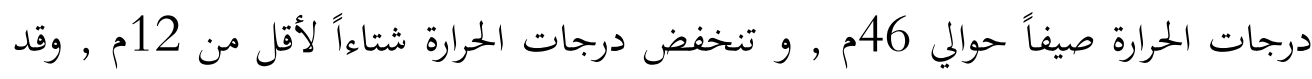

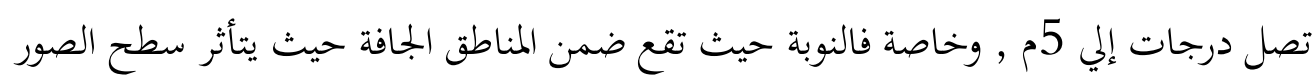

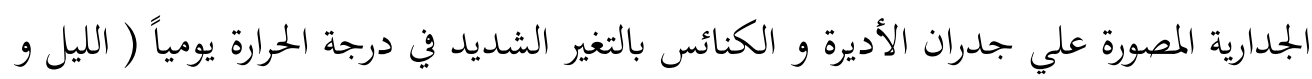

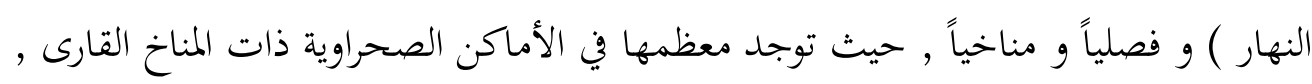

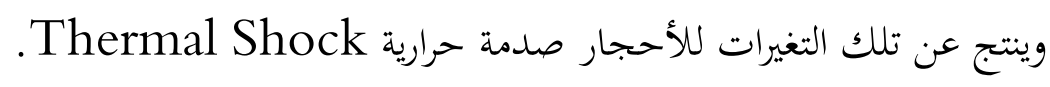

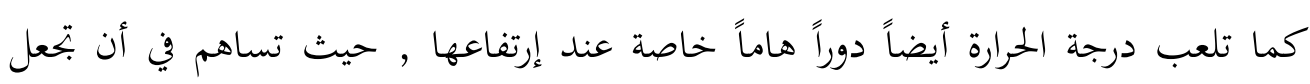

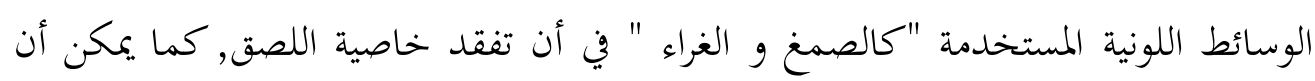

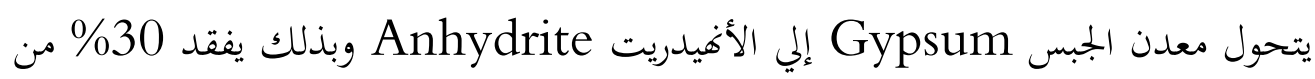

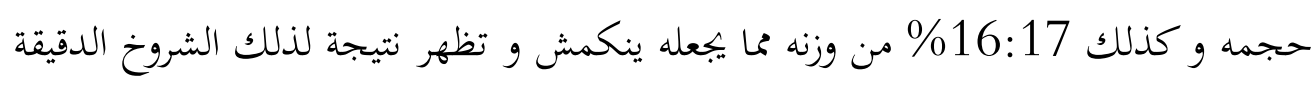
و الكبيرة وعمليات إنفصال لطبقات الملاط من السطح المنفذه عليه .

\section{: Moisture}

تعد الرطوبة من أهم عوامل و قوي التلف التي تساهم بدور فعال في معظم عمليات التلف

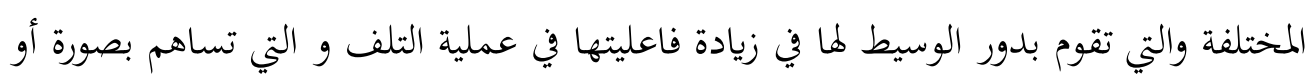

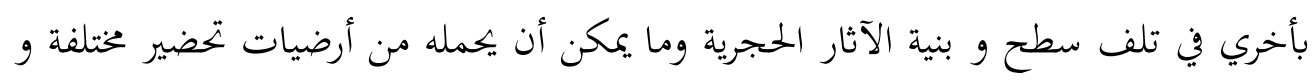

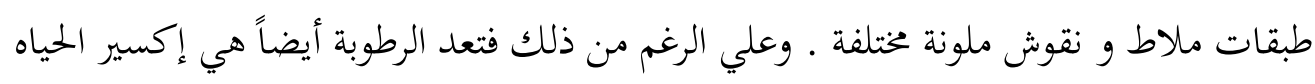

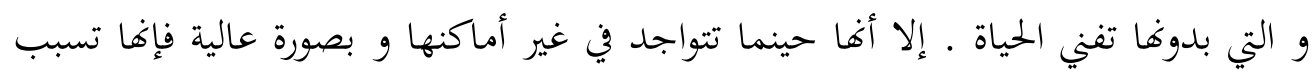

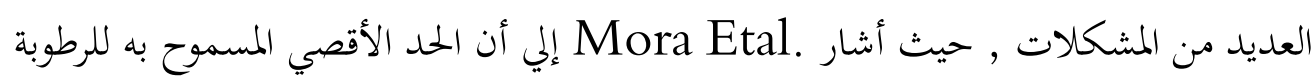

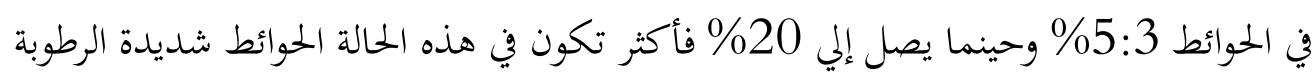

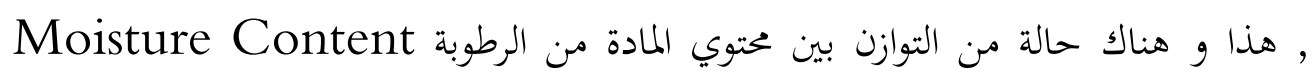


والرطوبة النسبية Relative Humidity في الوسط المحيط , فإذا زادت الرطوبة النسبية يزيد تبعاً لها متوي المادة من الرطوبة والعكس صحيح.

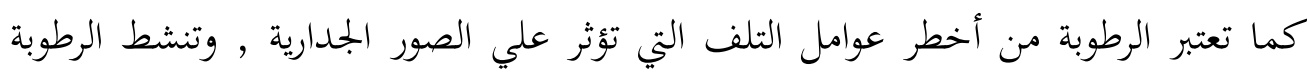

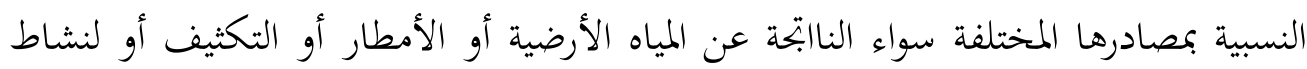

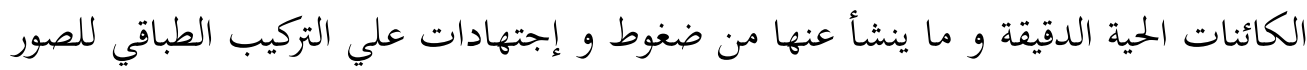

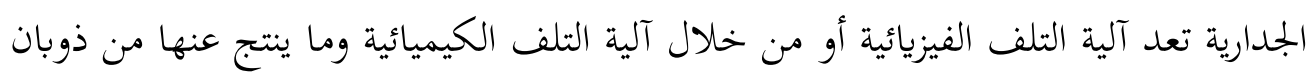

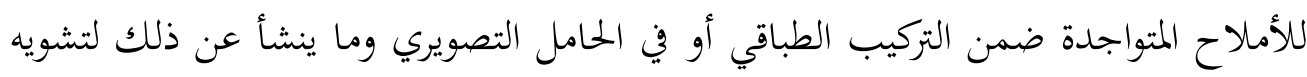
وضعف للتركيب الطباقي للصور الجدارية , ويككن تصنيف الرطوبة بناء علي مصادرها فمنها

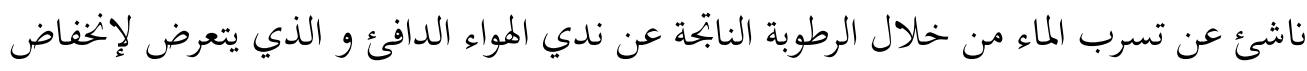

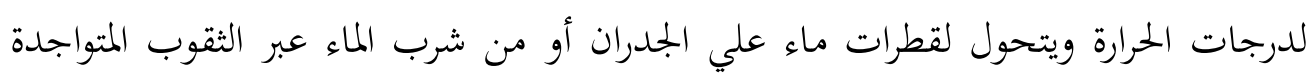

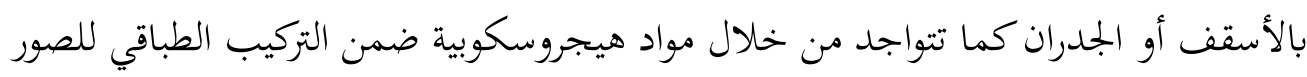

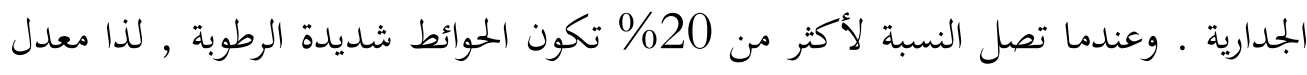

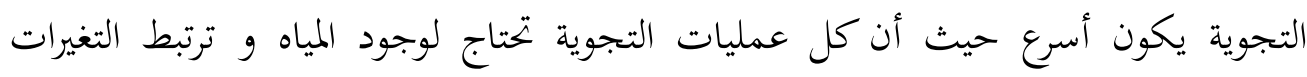

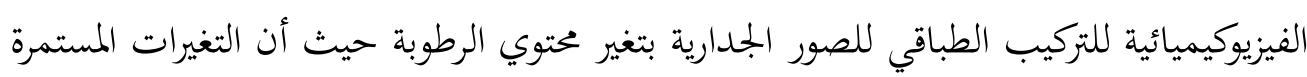

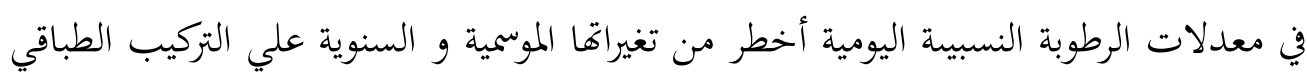

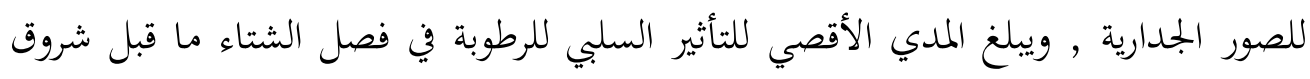

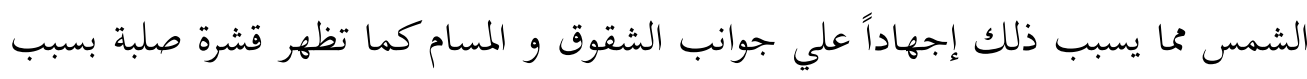

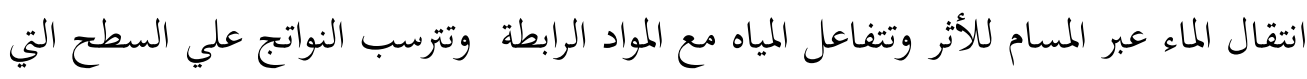

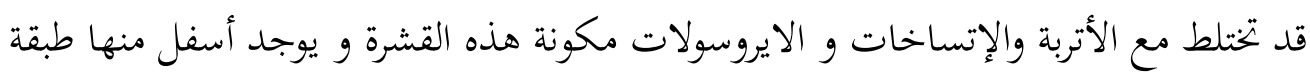

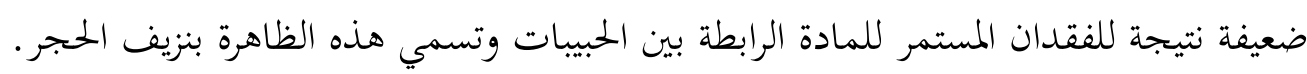
وهناك عدة مصادر مختلفة للرطوبة و التي بدورها تؤدي الي ارتفاع المتوي المائي داخل الأثر : إن

: Rains أ- الأمطار 
من الحقائق الثابتة أن المباني الأثرية والتاريخية الموجودة في المناطق الجافة قليلة الأمطار تكون أكثر بقاءاً وأكثر ثباتاً و تماسكاً من تلك التي توجد في المناطق الرطبة غزيرة الأمطار (7). تخضع مصر لنوعين من الأمطار : "أمطار الأنغاضات" وتسمي بالأمطار الاعصارية و " أمطار

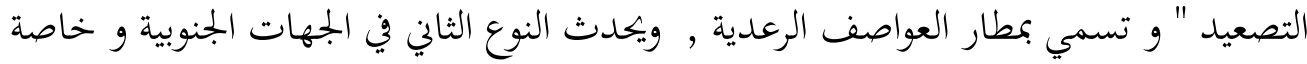

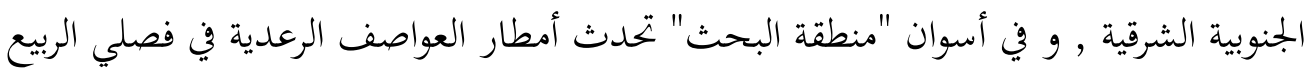

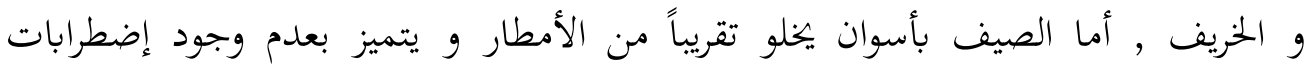

$$
\text { وهدوئه.(جدول 2) }
$$

أما فيما يتعلق بقلة الأمطار فإنها تعد قليلة جداً في أسوان و التي تدخل ضمن الإقليم الصحراوي

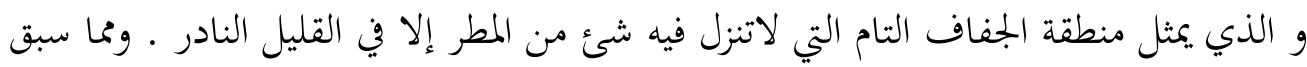

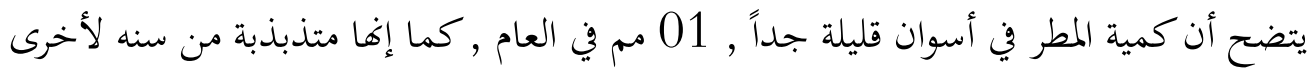

$$
\text { و من فصل لأخر ومن شهر لأخر. }
$$

وآليه تلف الأمطار تكمن في ـ عندما تبدأ جزيئات المياه التغلغل داخل الأسطح بواسطة المسام

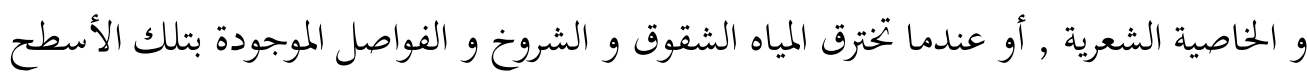
ـ وعند إنخفاض درجة الحرارة في الوسط الميط يحدث تجمد لهذه المياه داخل الشقوق و المسام

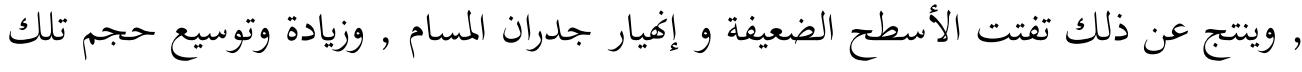

\begin{tabular}{|c|c|c|c|c|c|c|c|c|c|c|c|c|c|}
\hline & \multicolumn{3}{|c|}{ الخريـف } & \multicolumn{3}{|c|}{ الصيـف } & \multicolumn{3}{|c|}{ الرييه } & \multicolumn{3}{|c|}{ الشتـاء } & \\
\hline & 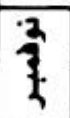 & 皇 & s. & 3 & a & +2 & 3 & 雾 & \begin{tabular}{|l|}
3 \\
3
\end{tabular} & $\frac{7}{4}$ & 7 & 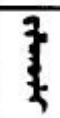 & \\
\hline r, & - & •, & - & - & - & - & - & 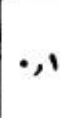 & - & - & - & - & 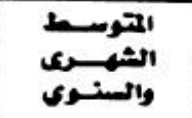 \\
\hline (..., & - & $m, v$ & - & - & - & - & - & - & $\pi, \nabla$ & - & - & - & 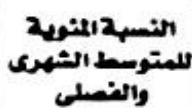 \\
\hline
\end{tabular}
الشقوق و الفواصل نتيجة تمدد المياه و زيادة حجمها عند التجمد (8). 
(جدول 2) يوضح المتوسط الشهري والسنوي والنسبة المئوية للمتوسط الشهري والفصلي

$$
\text { لعدد الأيام ذات العواصف الرعدية علي أسوان }
$$

ب - Relative Humidity الرطوبة النسبية

و هي نسبة كمية بخار الماء المتواجد فعلياً في حجم معين من المواء إلي النسبة اللازمة لتشبع هذا

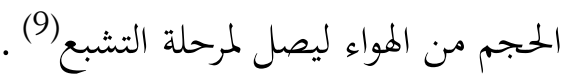
تعد الرطوبة النسبية عند زياداتا من المشكلات الخطيرة جداً , وأوقات يكون السبب الرئيسي

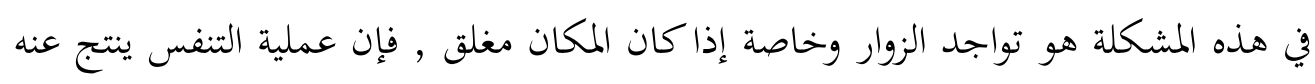

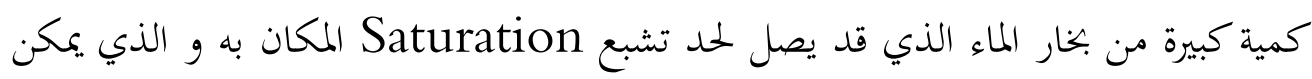

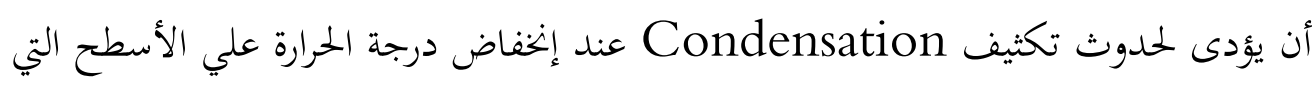
تحمل طبقات الملاط الملون مما قد يؤدي لتساقط وتلف معظمة .

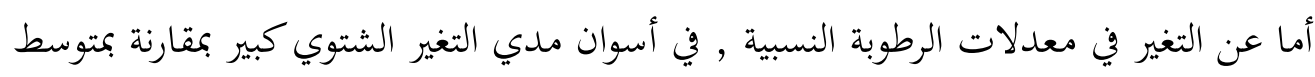

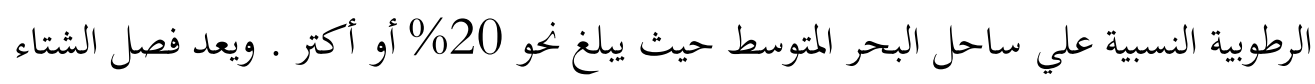

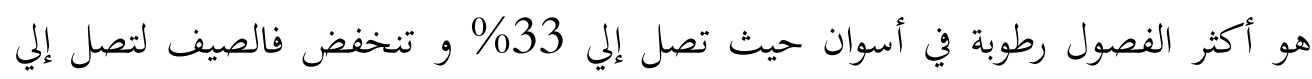
$\% 16$

\section{ج - Evaporation (البخر}

تتوقف كمية البخر في أي مكان علي عدة عوامل أههمها درجة حرارة الهواء , الرطوبة النسبية

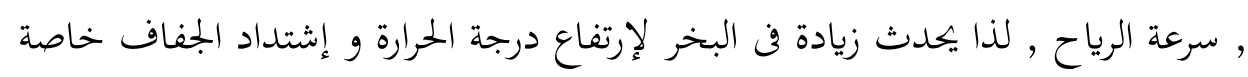

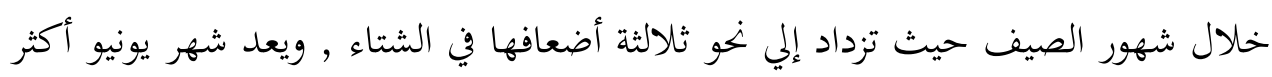

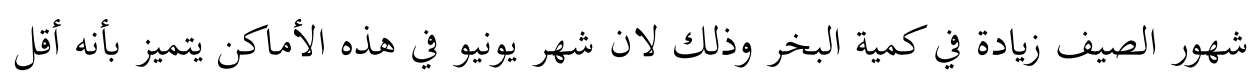
شهور الصيف رطوبة نسبية مع إرتفاع درجة الحرارة. 


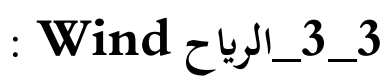

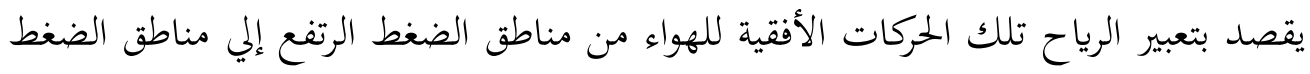

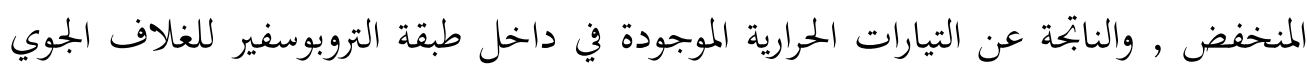

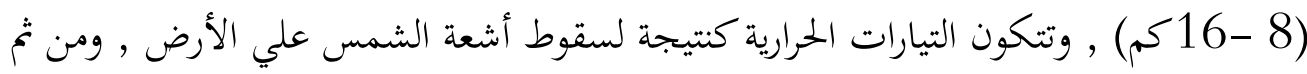

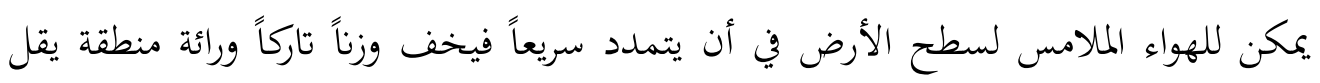

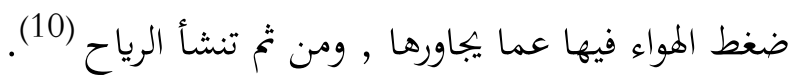
تختلف خواص الرياح من مكان لأخر علي سطح الأرض ومن موسم لأخر , وكذلك من ساعة

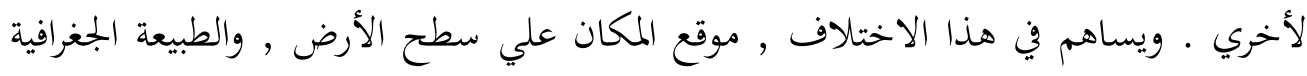

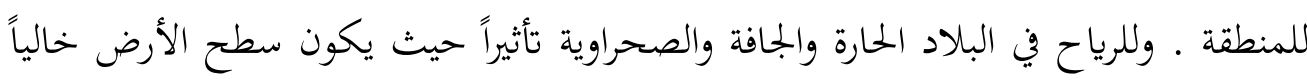

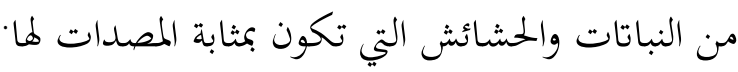
كما أن الرياح تعد من أهم عوامل التعرية وهي من الأسباب الرئيسية في عمليات هدم ونحر

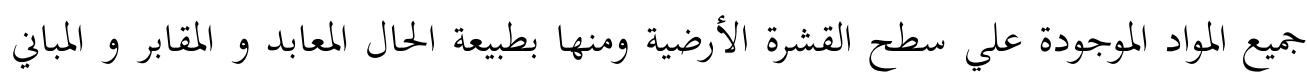
الأثرية.

وبقدر ما يعتبر هذا العامل في نظر كثير من الناس وكذلك في نظرنا نحن المرمون عامل هدم فإنه

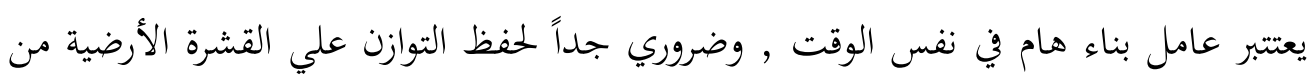

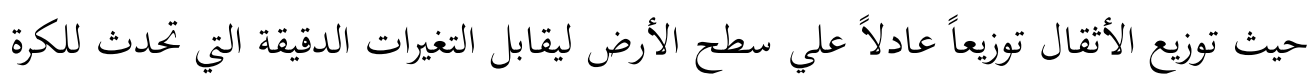

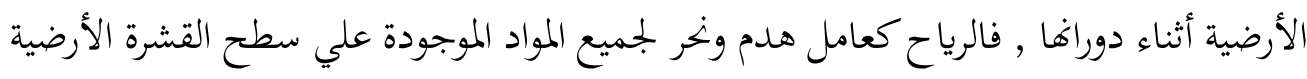

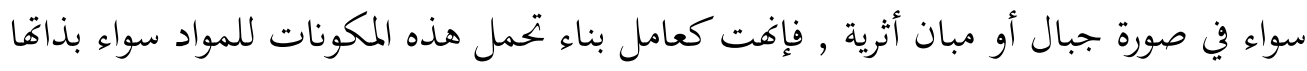

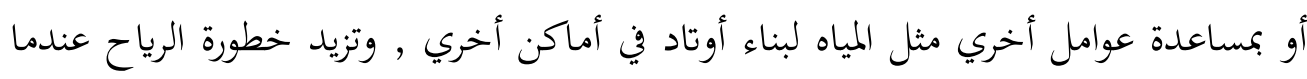
تزيد سرعتها عن 59كم / ساعة. 
ومما سبق كان لابد من عمل قياسات لسرعة الرياح علي مدينة أسوان في الأعوام السابقة من

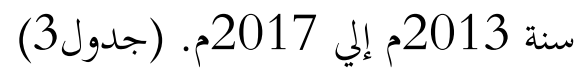

\begin{tabular}{|c|c|c|c|c|c|c|c|c|c|c|}
\hline \multicolumn{2}{|c|}{2017} & \multicolumn{2}{|c|}{2016} & \multicolumn{2}{|c|}{2015} & \multicolumn{2}{|c|}{2014} & \multicolumn{2}{|c|}{2013} & السئة \\
\hline يوليو & يناير & يوليو & يناير & يوليو & يناير & يوليو & يناير & يونيو & يناير & الثهر \\
\hline 106 & 27 & 40 & 26 & 37 & 26 & 34 & 26 & 47 & 40 & سرعة الرياح القصوى كمرسم \\
\hline 13 & 12 & 13 & 11 & 12 & 10 & 12 & 10 & 14 & 11 & المتوسط كم/سم \\
\hline
\end{tabular}

( جلول3) يبين سرعة الرياح القصوي و المتوسط علي مدينة أسوان في الشتاء و الصيف من سنة 2013م إلي 2017م.

ويتضح من خلال ما سبق أن الرياح تلعب دوراً هاماً في عمليات التلف , الأول كعامل بناء , والثاني الهدمي والذي يطلق عليه التحات الرياحي "النحر Wind "Erosion Abrasion • ويعمل نحر الرياح أكثر في المناطق الضعيفة خاصة مناطق وجود الطفلة وكذلك عند مستويات الترسيب والفواصل , كذلك تلك الأماكن التي تأخذ شكل الفجوات والمعرضة للرياح الشديدة

كما تعد الرياح من العوامل الهامة في تلف المنشأت الأثرية مما تحملة من رمال ناعمة وأتربة وملوثات جوية , فهي تعمل علي التاكل السطحي للمنشآت الأثرية و ما تحملة من صور جدارية , و يعتمد تأثير الرياح المتلف علي عده عوامل منها : سرعة الرياح , درجة حرارة الهواء , الرطوبة النسبية , طبيعة إصطدامها بالأثر , ومدة التعرض لها , نوعية و صلابة الأثر , ونوعية و أحجام و صلابة ماتحملة من حبيبات رملية .

والواقع أن معدل تآكل المباني الأثرية بفعل الرياح يزداد بدرجة ملحوظة إذا حدث وفقدت مواد

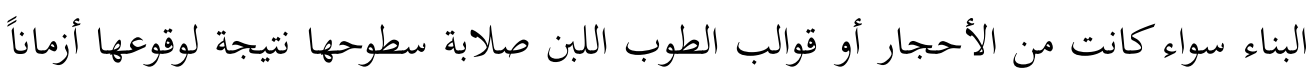


طويلة تحت تأثير التغيرات الكبيرة في درجات الحرارة في ساعات الليل والنهار وفي فصول السنة المختلفة أو نتيجة للتحولات الكيميائية و المعدنية التي تصاحب تعرضها لدرجات حرارة مرتفعة

كما تلعب الرياح دوراً خطيراً في خلخلة الاتزان حول الأثر و المتمثل في اتزان معدلات الرطوبة

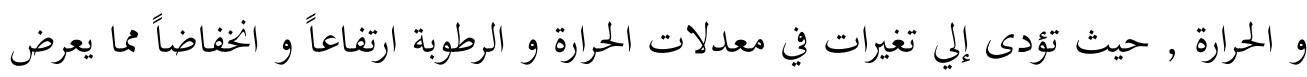

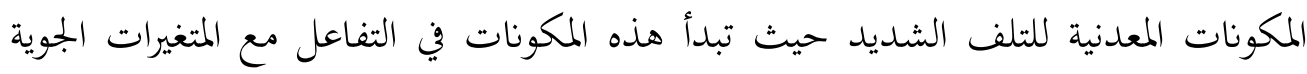

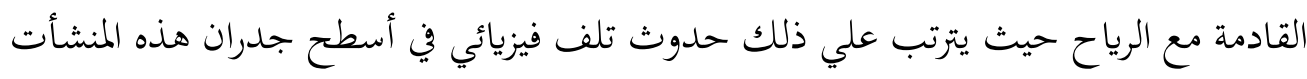
الأثرية(11)

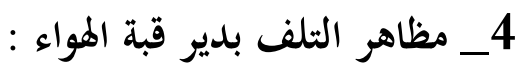

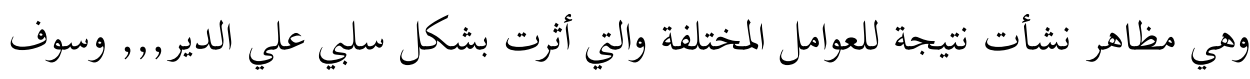
نقوم بسرد كل عامل مناخي علي حدا وما ينتج عنه من ظاهرة خختلفة.. 


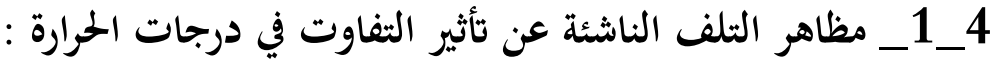

أ - حدوث شروخ و تشققات و تشوهات خارجية وداخلية في مكونات الصور الجدارية نتيجة للتأثر الفيزيائي الناشئ عن التفاوت في درجات الحرارة. (صورة 4)

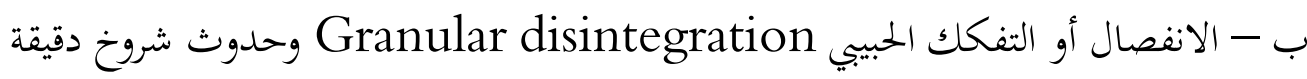

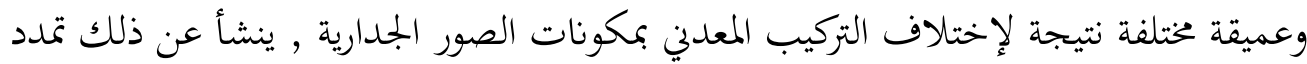
للتركيب المعلني علي حسب قدرته التمددية كبلورات الكالسيت يمدث تمدد بدرجات مختلفة

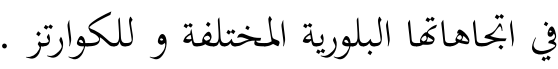

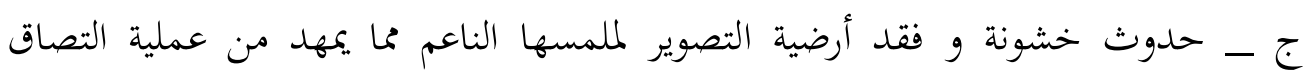
الاتساخات و الأتربة بالتصوير الجداري .

د - حدوث بهتان لوني في أرضية التصوير و للمواد الملونة المختلفة. (صورة 5)

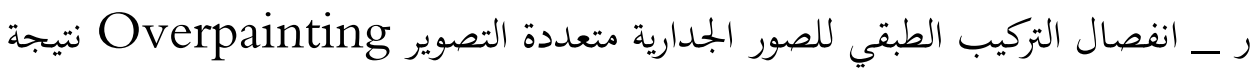
لإختلاف تأثر طبقات الصور الجدارية بدرجات الحرارة المختلفة (12).

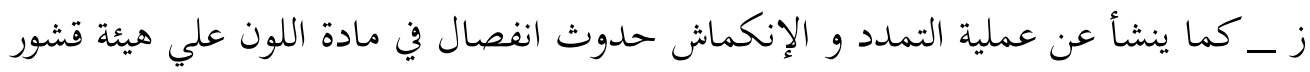

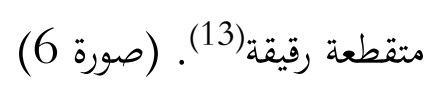
و _ كما يؤدى التمدد الذي يحدث للأحجار نتيجة تفاوت درجة الحرارة من إرتفاع و إنخاض إلي حدوث فوالق وشروخ بجدران المبني الأثري. 

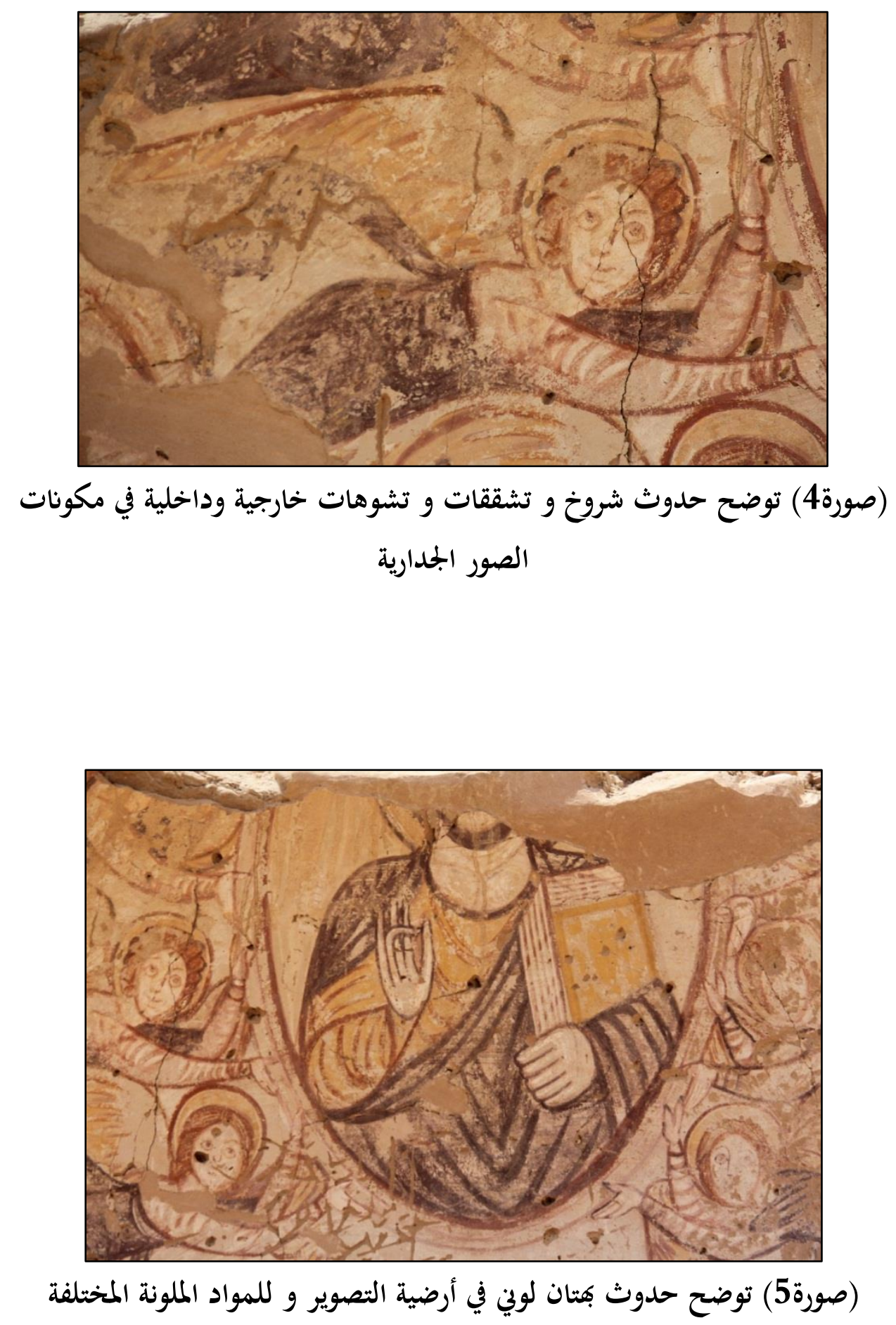


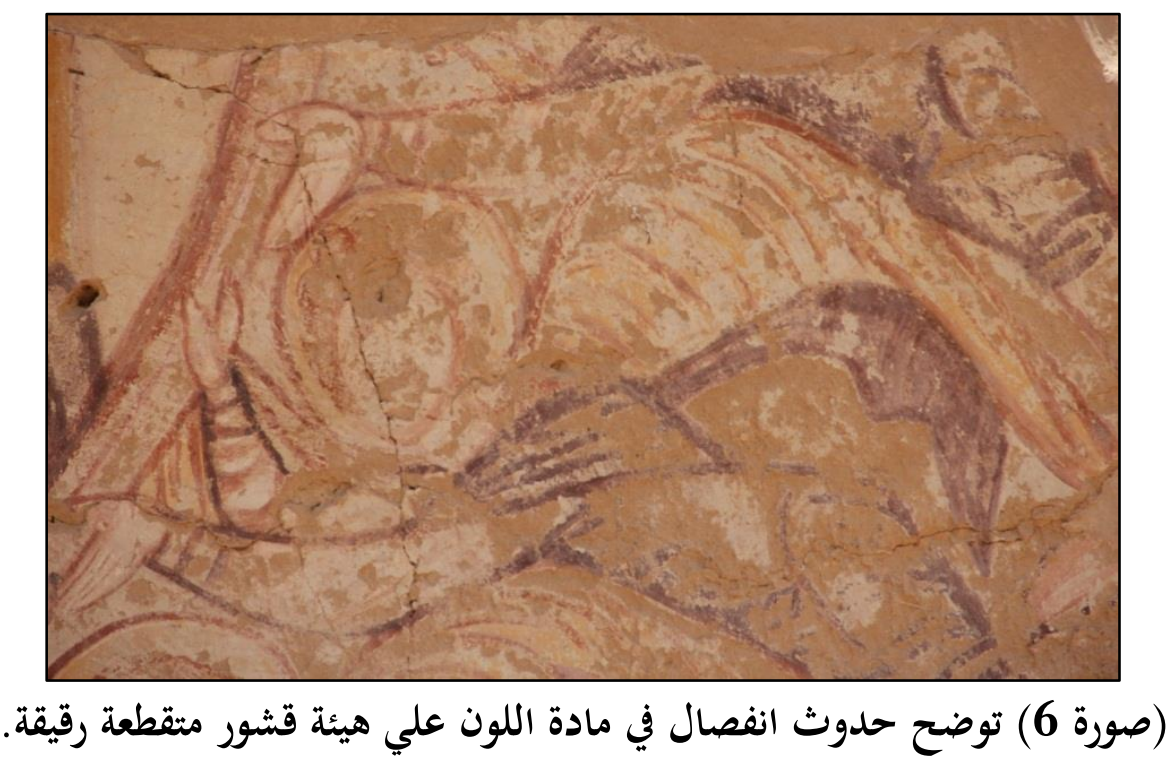




\section{: 4 4_2_2}

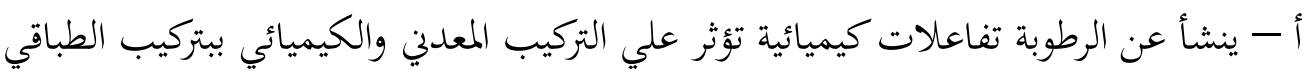
من خلال دورات البلل والجفاف المؤدية لظهور أشكال للتجوية ناشئة عن الضغوط الميكانيكية. ب - يؤدي التعرض المستمر للرطوبة الجوية الي تنشيط التجوية الكيميائية عن طريق تبلور التهال

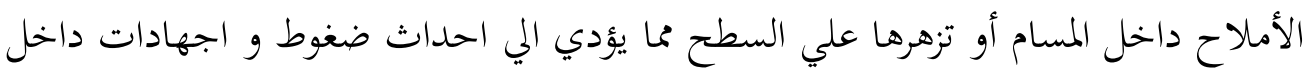

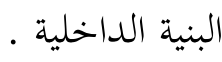

ج ـ تسبب تزهر الأملاح علي السطح في حدوث خشونة وفقد السطح لملمسة الناعم المصقول

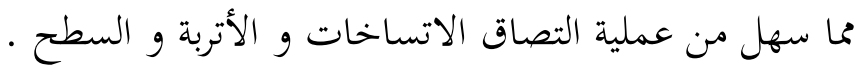

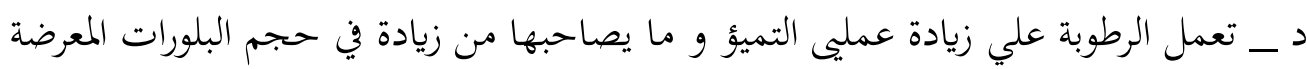

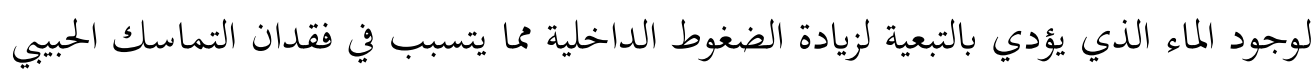

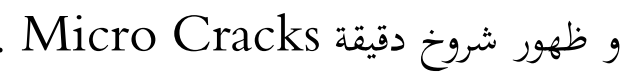
ر ـ تسبب الرطوبة ظاهرة التفتيح للألوان المعتمة Blooming أو تسبب المظهر المعتم The opaque appearance س ـ انخفاض المتوي المائي داخل التركيب الطباقي للصور الجدارية يخلق حالة من عدم التوازن

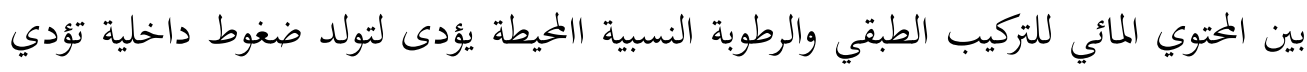

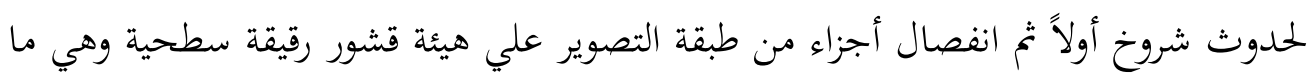

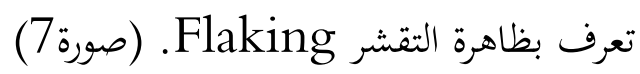




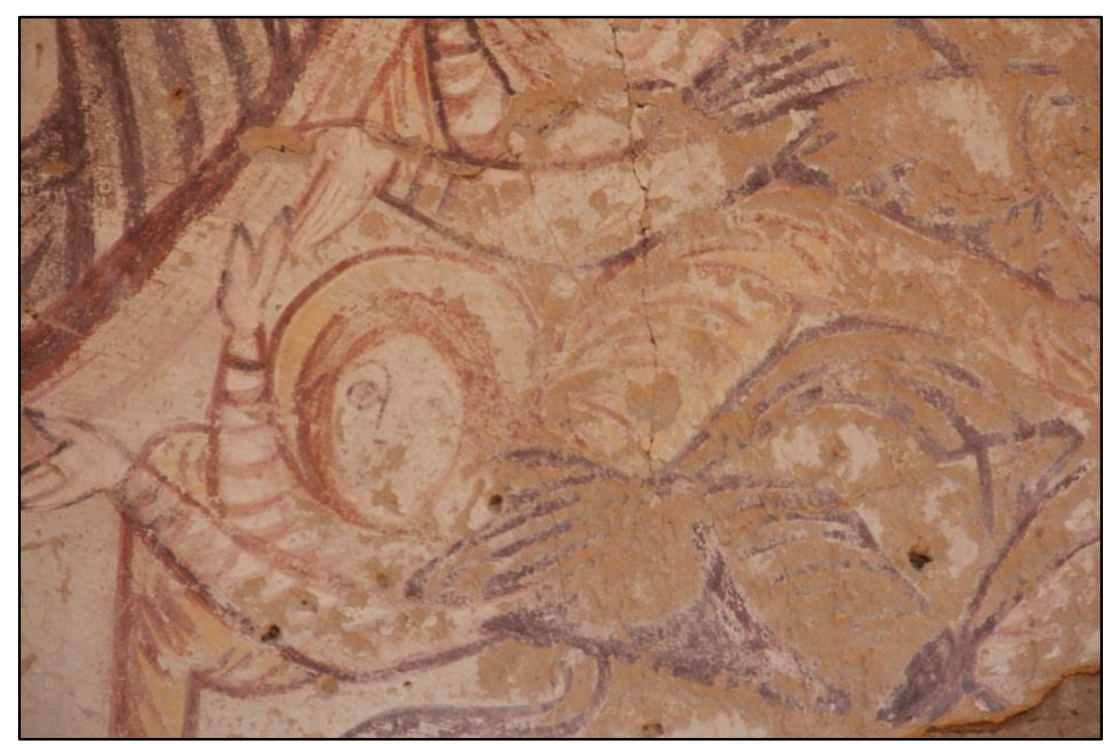

( صورة 7) توضح شروخ أولاً ثم انفصال أجزاء من طبقة التصوير علي هيئة قشور رقيقة

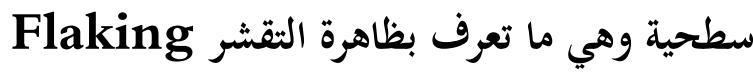

\section{:}

أ - زيادة سرعة الرياح تسبب التآكل النحري و التآكل الحفري و تعمل علي جعل التعل أسطح

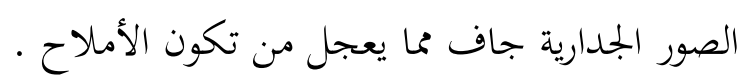

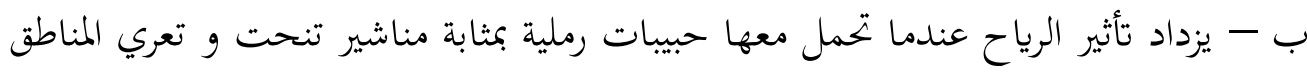

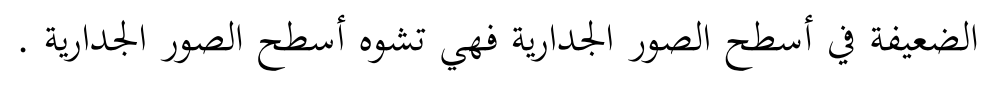

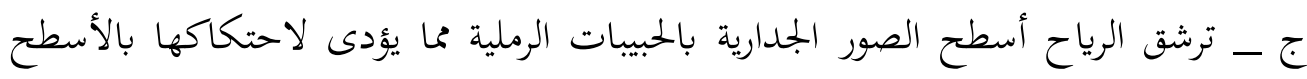

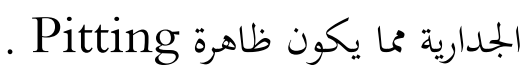

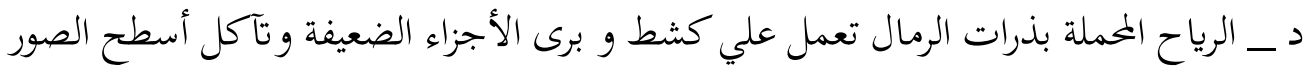
الجدارية بدرجات مختلفة حسب صلابة الأسطح ونوعية الترابط البيني . 
رـ تعمل الرياح على وجود فجوات في السطح و تسبب لوناً داكناً أو تؤدي لسواد الأسطح

س - تقوم الرياح بعمل حفر تذرية و تقوم في الأماكن الصحراوية بنقر الأسطح. (صورة 8)

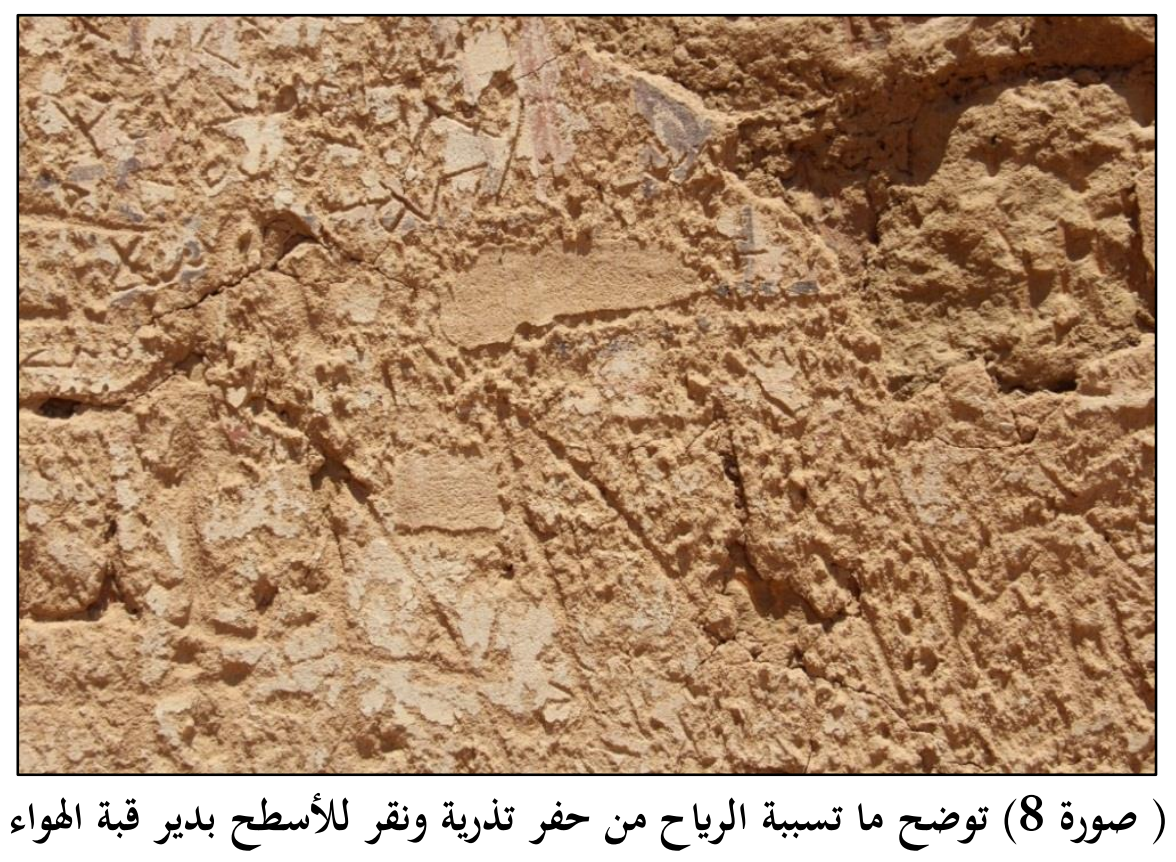


(1) نبيه كامل ,عاطف نجيب : " تاريخ المسيحية وآثارها في أسوان والنوبة", مؤسسة القديس مرقس لدراسات التاريخ القبطي,

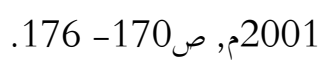

محافظة_أسوان./ar.wikipedia.org/wiki (2)

. https://www.google.com.eg/intl/ar/earth (3)

(4) حسين محمد علي : "دراسة علاج الصور الجدارية و صيانتها بمنطقة آثار المنيا ", دكتوراه , قسم ترميم الآثار , كلية الأداب , جامعة أسيوط , ص ص 98.

(5) عاطف عبد اللطيف عبد السميع : "دراسة مقارنة لعلاج و صيانة مقابر نبلاء أيليفنتين الصخرية ( قبة الهواء) بأسوان "

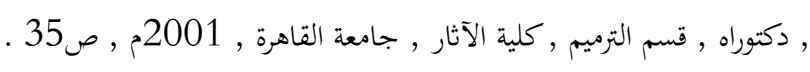

(6) صالح أمد صالح : "الأسس العلمية لعلاج و صيانة الآثار الحجرية ", محاضرات بقسم الترميم , جامعة القاهرة , 1986.

(7) عبد المعز شاهين : " ترميم و صيانة المباني الآثرية التاريخية " , البجلس الأعلي للأثار المصرية , وزارة الثقافة , 1994م , ص 172.

(8) ريهام عدلي سالم : " ترميم الصور الجدارية بالعمارة الجنائزية بمنطقة تونا الجبل بالمنيا " , قسم الترميم ركلية الفنون الجميلة

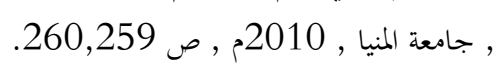

(9) جورجيو توراكا : " تكنولوجيا المواد و صيانة المباني الأثرية " , ترجمة : د/ أمد عطية , دار الفجر للنشر , القاهرة , 2003م , صورجو تراك. :

(10) عاطف شريف : "الهواء و تأثيرة علي المنشأت" , ندوة جامعة القاهرة , الرؤية العلمية للحفاظ علي الآثار , القاهرة , 1990م , ص صاطن

(11) عممد عبد المادى : " دراسات علمية في ترميم وصيانة الآثار غير العضوية " , مكتبة زهراء الشرق , القاهرة , 1997م. 
(12) أحمد محمد سلام حسن : " دراسة علاج وصيانة الرسوم الجدارية القبطية في النوبة " , دكتوراه , قسم الترميم , كلية

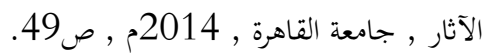

(13) بجدي منصور بدوي : " علاج وصيانة بعض أيقونات التمبرا في مصر طبقاً لأحدث الأساليب التطبيقية العلمية الحديثة

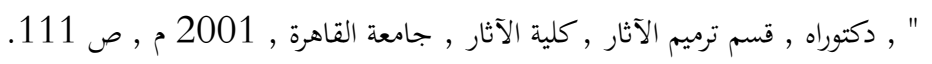

(14) حسين حسن مرعي : "نو إستراتيجية علمية لطبقات البلاستر المنفذه علي حوامل الحجر" , ماجستير , قسم الترميم كلية الآثار , جامعة القاهرة , 2004م , ص 77 , 